\title{
Development Impact on Pokkali Fields A Case of International Container Transshipment Terminal,
}

\author{
Vallarpadam, Kochi Agile Joy \\ (Department of Economics, Sacred Heart College, Thevara, India)
}

\begin{abstract}
Development always demands displacement as well as compromising the quality of environment. There is no doubt that the Vallarpadam Container Transshipment Terminal is a boost to Kerala economy as well as for the country's international trade scenario. But this project has done an irrevocable damage to our coastal areas where Pokkali indigenous organic rice cum prawn culture was practiced. The Pokkali-Prawn rotational culture system plays a very important role in maintaining the environmental quality as well as protecting our rich ecosystem. Due to this development project lot of people were displaced and hectares of wetlands were converted. The people who are displaced they not only lost their land but also their livelihood. The people who were traditionally practising Pokkali cultivation were generally unskilled and they are not able to move to any other occupation for meeting their ends. The damage done in the name of development to the environment as well as to the people is to be discussed seriously.
\end{abstract}

Keywords - Environment, Development, Displacement, Pokkali, Wetlands

\section{Introduction}

Development and environment are interrelated and having mutual impacts on each other. Improper or uncontrolled development is likely to cause adverse impacts on the environment, and environmental pollution or degradation may become a major obstacle for social and economic development. All development projects in one way or another cause damage to the environment and to the people. Whenever human beings try to improve their living standards they were destroying the natural habitats of thousands of living organisms including man himself. Infrastructure development in the form of roads, railways and other lines of communication fragmented the contiguity of the wetlands and destroyed extensive tracts of coastal vegetation thereby upsetting the entire complex ecology. Rapid urbanisation encroached into the rich and luxurious mangrove forests, while industrial development not only caused pollution but prevented any regeneration possibilities as well. The degradation of the wetlands of Kochi is not an isolated event. Worldwide, wetlands are in peril. They are either being polluted, drained or filled up to give way for development. The wetlands are now the most threatened ecosystems of our planet.

\section{Wetlands in Kochi}

Kerala is one of the 'Green States' of India and is well known for its wetlands. There are about 217 wetland areas in Kerala and it accounts for as much as one fifth of the land area of the state. The district of Ernakulam tops with $20.26 \%$ of the total state's wetland extent followed by Alappuzha (15.8), Trishur (12.99) and least by Wayanad (0.8). Vembanad Wetland is spread over the districts of Alappuzha, Kottayam, Ernakulam and Thrissur of Kerala. It is the longest water body in the country and largest in the state. The wetland has an area of $1521.5 \mathrm{~km} 2$ and volume of $0.55 \mathrm{~km} 3$, fed by 10 rivers flowing into it, adding up to a total drainage area of $15,770 \mathrm{sq} \mathrm{km}$. It is a complex aquatic system of $96 \mathrm{~km}$. long coastal backwaters, lagoons, marshes, mangroves and reclaimed lands, with intricate networks of natural channels and man-made canals.

Wetlands occupy the transitional zone between the aquatic and terrestrial environment sharing the characteristics of both of them, and are unique in their own way. Scientists often refer to wetlands as the 'kidneys' of the earth. Wetlands support a wide array of flora and fauna and deliver many ecological, climatic and social functions. These wetlands provided livelihood to the residents in the area in the forms of agricultural produce, fish, fuel and a host of other day to day necessities. As long as human intervention remained minimal, the ecosystem, through its all-encompassing balancing nature was self-cleansing. But the development demands that determine the choice of the paths upset the natural harmony.

\section{Pokklai Fields in Kochi}

Kerala state has a coastline of $560 \mathrm{~km}$. This coastal belt has a unique system of rice cultivation in the saline soils known as pokkali cultivation. The Pokkali field is a unique ecosystem prevailing in the coastal saline tract of central Kerala with rich biodiversity and amazing capacity to generate organic paddy and shrimp alternatively. According to Pokkali Land Development Agency officials, there used to be some 25,000 hectares 
of Pokkali fields in Kerala a few decades ago, but now the extent is down to roughly 9,000 hectares. From various studies it is very clear that year by year the area under Pokkali cultivation is declining. There are about 4,000 hectares of paddy fields under pokkali cultivation in Ernakulam district, while in Alappuzha and Thrissur the extent of pokkali cultivation is in about 3,000 hectares and 2000 hectares respectively. At present only 2,000-3,000 hectares, mainly on the islands in the Kochi backwaters and Vembanad Lake, are under cultivation. Some areas like Kumbalangi, Udayamperoor, Cheranalloor, Chellanam, Eloor, Kadamkudi, Varapuzha, Edavanakaddu, Moolampally and Puthuvype of Ernakulam District are mostly marshy and waterlogged. These marshy tracts lie near the mouth of the rivers and are close to the sea. Therefore, they are prone to flooding and salinity. The nature of the soil is also highly acidic and has elemental toxic content, making the area uncongenial for paddy cultivation. But the Pokkali paddy, which to an extent is saline, flood and acid-resistant, is the wonder crop which is cultivated in these parts. Paddy cultivation is practiced in Pokkali tracts during the low saline phase and prawn farming is practiced during the high-saline phase. What is really interesting here is that absolutely no chemical pesticides or fertilizers are used in the Pokkali rice fields, making it vastly different from the other prevalent farming practices. Pokkali rice is perhaps the strongest among rice varieties and able to survive the high salinity and acidity in marshy areas bordering the sea. 'Pokkali Rice' is cultivated in traditional and natural ways. It is also highly environment-friendly and poison free.

Pokkali is the oldest variety of rice in Kerala - South India, which has a tradition of at least 3000 years in rice cultivation. It is also among the oldest known crops cultivated by organic farming methodologies in the world. In rice cultivation, the Pokkali variant has remained a favourite among many farmers and now attained global recognition as well as exclusive cultivation and distribution rights to its Kerala growers, standing out as a befitting recognition of its superiority. Pokkali Rice', a traditional salt-resistant rice variety cultivated in the coastal regions of Ernakulam, Alappuzha and Thrissur Districts in the State of Kerala - India, has been awarded the status of registered Geographical Indication (GI) by the Geographical Indications Registry Office, Chennai, Tamil Nadu.

The practice of taking a paddy crop followed by prawn filtration practice provide labour and regular income to the farmers all-round the year [1]. The stubble and residues of the paddy crop left after harvest creates a favourable situation for the growth of prawn in the succeeding future. The fish and prawn in the field feeds on the pest and disease carrying weeds and stubble of the paddy left in the field and hence favours the ensuing paddy crop. Then the excreta of the shrimps will be nutritious fertiliser for the pokkali paddy crop. It is purely an organic cultivation without any chemical fertilizers, manure or insecticides. It is a natural indigenous way of cultivation that relies on the monsoon and the sea tides.

\section{The Vallarpadam Project}

Cochin (Kochi), Queen of the Arabian Sea is believed to be the finest natural harbour in the world. Cochin is the oldest European settlement in India recording a history of visitors who came, saw and stayed for hundreds of years. Layered impressions - Chinese, Arab, Jewish, British, French and Portuguese, are contained within its environment.

In the recent history of Kerala especially for Kochi, one of her milestone is the establishment of International Container Transhipment Terminal (ICTT), locally known as the Vallarpadam Terminal, is a container trans-shipment facility which is part of the Kochi Port. The terminal paved way for an increased connectivity through new bridges, national highways, rail links and through the waterways. In short, Kochi's trade links will increase tremendously. Vallarpadam Island where the International Container Transhipment Terminal is located is connected to main land by constructing bridges across the bays and a container terminal road connecting Vallarpadam with NH 47 and NH17. A railway link is also constructed inorder to handle the containers at Vallarpadam Terminal in Kochi, Kerala. It is the longest rail bridge in India. The $4.62 \mathrm{~km}$ rail bridge is part of an $8.86 \mathrm{~km}$ rail corridor connecting the International Container Transshipment Terminal (ICTT) on Vallarpadam Island with Edappally, a suburb in Kochi city. The Vallarpadam-Edappally / Idapalli railway connects the existing Southern Railway Network. For all these projects most of the land acquired are the wet lands commonly known as the Pokkali Fields, where paddy and prawn were grown in an indigenous and organic way.

\subsection{International Container Transshipment Terminal}

The Kochi International Container Transhipment Terminal (ICTT), locally known as the Vallarpadam Terminal, is a container trans-shipment facility which is part of the Kochi Port. It is the only trans-shipment port in India, and is situated in Kochi, in the state of Kerala. On 16 February 2005, Dubai Ports World announced that it has formally signed an agreement with the CoPT to construct, develop and operate an International Container Transshipment Terminal (ICTT) - An India Gateway Terminal - at Vallarpadam. Strategically, located on the main east-west global shipping lines and offering draft of about $16 \mathrm{~m}$, Cochin is destined to develop as the premier gateway to southern India, as also offering an alternative to Sri Lanka and 
Singapore for containers being transshipped for the Indian market. On 11 February 2011 the terminal was inaugurated by the Mr. Manmohan Singh, Prime Minister of India. The ceremony was attended by A. K. Antony , G. K. Vasan, K.C. Venugopal, R. S. Gavai, V. S. Achuthanandan , K. V. Thomas, Vayalar Ravi , C P Joshi, Mullapaly Ramachandran, N Ramachandran.

\subsection{Vallarpadam Container Terminal Road}

Vallarpadam Island where the International Container Transhipment Terminal is located is connected to main land by constructing bridges across the bays connecting Vypeen Island with Vallarpadam, Vallarpadam with Bolghatty Island and Bolghatty Island with Ernakulam Town and which had been done by Goshree Island Development Authority. With the functioning of the new ICTT at Vallarpadam the intensity of vehicular traffic over this route will be very high and will cause continuous traffic blockage. Hence, an alternate proposal for connecting Vallarpadam with NH 47 and NH17 was proposed by constructing this Project Corridor. The fourlane $\mathrm{NH}$ which will be known as $\mathrm{NH}-47 \mathrm{C}$ is one of the pre-requisites to the setting up of the Rs 2,118-crore International Container Transhipment Terminal project of the Kochi Port at Vallarpadam. The new NH connectivity to the terminal at Vallarpadam comprising of four lane road and bridges with a route length of 17.2 $\mathrm{km}$ from Kalamassery to Vallarpadam is executed by NHAI. The total land required for acquisition is 90.95 hectares and it is estimated that Rs 55 crores would be needed to provide as compensation to families affected with the acquisition. The estimated cost is Rs. 872 crores. The connectivity comprises of a Fly-Over along NH 47, 11 Major Bridges and a Minor Bridge across back waters connecting various islands. The road, constructed by the National Highway Authority of India, will start from the second bridge of the Goshree Island Development Authority (GIDA) and stretch across the Kochi suburbs of Bolghatty, Mulampilly, Kothad, FACT Gypsum Ground to reach Kalamassery. Cochin Port Trust was entrusted with the work of handing over of 6.70 $\mathrm{Km}$ of land by dredging in the back waters and forming embankment along the back waters, which was completed by the Port in August 2009. The two lane connectivity was completed in October 2010 and work of the additional two lanes is in progress. Tentative target date of final completion of the Project has been assessed as December 31, 2013.

Land acquired for Vallarpadam Container Terminal Road

\begin{tabular}{|l|c|c|}
\hline Village & Total land acquired (ha) & Wetland acquired (ha) \\
\hline Mulavukadu & 11.5511 & 11.4298 \\
\hline Cheranalloor & 9.2634 & 1.1487 \\
\hline Kadamakudi & 13.4692 & 6.5546 \\
\hline Varapuzha & 0.19 & 0.19 \\
\hline Eloor & 10.2244 & 3.5548 \\
\hline Thrikkakara North & 0.3129 & - \\
\hline Kadungalloor & 1.4176 & 0.56 \\
\hline Total & $\mathbf{4 6 . 4 2 8 6}$ & $\mathbf{2 3 . 4 3 7 9}$ \\
\hline
\end{tabular}

Source: Kerala Gazette Extraordinary Publication. No. 2149 date: 27-09-2005

Kerala Gazette Extraordinary Publication. No. 2573 date: 29-11-2005

For the national highway connecting the Vallarpadam Container Terminal and with Kalamassery, a nearby town, 46.4286 hectares in seven villages have been acquired, evacuating 183 families. From these acquired land around $50 \%$ are the pokkali fields where rice and prawn are cultivated in an organic rotational culture system.

\subsection{Vallarpadam Railway Link}

Rail Vikas Nigam Constructed a railway line to the vallarpadam terminal with a total length of $9.3 \mathrm{~km}$, in which $4.62 \mathrm{~km}$ through Vembanad Bridge, which become the longest railway bridge in India. The rail-link forms a crucial project for commissioning operations of the ICTT as it will be exclusively used for goods container traffic to and from the terminal. Work on the bridge started in October 2007 and was completed in March 2010. About $80 \%$ of the Vallarpadam Bridge is constructed over the backwaters of Vembanad lake. The latest construction technology such as launching girders machines and concrete pumping were used during bridge construction. A successful trial run was conducted on March 31, 2010 on the route. The railway line and allied infrastructure were built at a cost of Rs. 350 crores and was entirely funded by the Central Government through the Ministry of Shipping. The client for the railway line project was Rail Vikas Nigam (RVNL), a Public Sector undertaking of Indian Railways. The Vallarpadam railway bridge passes through three small islands, including the Idyakkara and Mulavukadu islands, before finally reaching Vallarpadam. About $80 \%$ of the bridge is constructed over the backwaters of Vembanad Lake.

\section{Land acquired for Vallarpadam Railway Link}




\begin{tabular}{|l|c|c|}
\hline Village & land acquired (ha) & Wetland acquired (ha) \\
\hline Edappally North & 2.1384 & 0.299 \\
\hline Edappally South & 0.6135 & 0.1105 \\
\hline Cheranalloor & 2.1659 & 0.7345 \\
\hline Mulavukadu & 1.8342 & 0.7500 \\
\hline Total & $\mathbf{6 . 7 5 2}$ & $\mathbf{1 . 8 9 4}$ \\
\hline
\end{tabular}

Source: Kerala Gazette Extraordinary Publication. No. 349 date: 24-02-2007

The Ernakulam district administration has acquired 6.752 hectares in four villages for the railway line connecting the Vallarpadam Container Terminal with Edappally railway station. The proposed railway line will be $9.3-\mathrm{km}$ long. According to M Beena, district collector, 144 families were evacuated for the proposed railway line.

\section{Impact on Pokkali Fields}

The direct impact of these development projects on Pokkali field is seen in the form of reduction in the area of cultivation. For this project around 26 hacters of pokkali fields were acquired from Ernakulam district. Majority of the pokkali fields which are near to the water bodies were acquired for establishing these projects. This hinders the natural flow of water to the pokkali fields and as a result artificial water management using pump sets became necessary in these areas.

Construction of Vallarpadam Container Terminal Road and the Rail way Link hinder the natural flow of tidal waves into the pokkali fields. The traditional way of prawn farming in pokkali fields are purely on the basis of tidal waves. The juvenile prawn seedlings, which swim in from the sea and the backwaters are guided to the fields through trap sluices and the sluice gates prevent them from going out. Thus they are allowed to grow in the field. As a result of land acquired for this project farmers are not able to cultivate their land on a natural way; instead they have to depend on artificial method of cultivation.

The indirect effect is the booming of land prices in the nearby areas of Vallarpadam terminal. The terminal is sure to help various other industries to thrive and lead to an increased demand for workforce. A rise in workforce would lead to an increased need for office complexes and accommodation facilities. As such, these prospects would kindle a new interest in the real estate sector. In short, it will enhance Kochi's position as a favoured destination for the real estate investors, occupiers and developers. This encourages the farmers to stop the practice of cultivating pokkali and prawn in an organic way. Most of the Pokkali fields were purchased by MNCs and Builders.

Without Pokkali cultivation, the entire cultivated area would have been flooded and wasted; acidity and toxicity would be high and there would also be less oxygen and more hydrogen sulphide in the land. These waterlogged, swampy fields have no use for other than real estate developments.

The huge loss of wetlands also disturbed the ecological balance in these areas. These wetlands provided livelihood to the residents in the area in the forms of agricultural produce, fish, fuel, fiber, fodder, and a host of other day-to-day necessities. The presence of wetlands helped in providing drinking water besides reducing the impact of beach erosion. It also played a key role in biodiversity conservation.

As a consequence to the above mentioned reasons the dream of food security for our state will not be realised with the destruction of pokkali fields in the name of development.

\section{Conclusion}

To enhance the pace of economic development we do need projects like Vallarpadam Container Terminal, Railway Link and National highways. But the development demands that determine the choice of the paths never upset the natural harmony. Infrastructure development in the form of roads, railways, and other lines of communication fragmented the contiguity of the wetlands, and destroyed extensive tracts of coastal vegetation. Given the ever-increasing demands on our waters, we need more than ever to protect and restore these precious resources and the beneficial functions they offer. State would face serious environmental issues, if immediate steps were not taken to conserve the wetlands. Here what we need is sustainability: there are four key dimensions to sustainability - economic, institutional, social and environmental sustainability. All are important, and a livelihoods approach seeks a balance between them, which will often mean compromises and trade-offs will need to be made [2]. For protecting our wetlands the traditional practice of cultivating pokkali along with prawn farming can play a major role. Pokkali the oldest variety of rice in Kerala - South India, which has a tradition of at least 3000 years, is highly environment-friendly and also sustainable. Thus, through popularising the organic pokkali-prawn rotational farming practice we can protect our valuable wetland resources as well as can maintain the ecological balance for a better tomorrow.

\section{References:}


[1]. Jayan P R, Nithya Sathyanathan, Overview of farming practices in the water-logged areas of Kerala, India, International Journal of Agriculture \& Biological Enggineering, Vol. 3 No.4, 2010.

[2]. Allison, E. H. and Ellis, F. 2001. The Livelihood Approach and Management of Small-scale Fisheries. Marine policy 25: 377-388. 